\title{
Radiation exposure of adrenal vein sampling: a German Multicenter Study
}

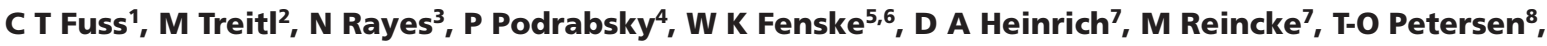 \\ M Fassnacht ${ }^{1}$, M Quinkler ${ }^{9}$, R Kickuth $^{10}$ and S Hahner $^{1}$
}

${ }^{1}$ Department of Medicine I, Division of Endocrinology and Diabetology, University Hospital, University of Würzburg, Würzburg, Germany, ${ }^{2}$ Department of Clinical Radiology, Ludwig-Maximilians-University, Munich, Germany, ${ }^{3}$ Department of General, Visceral and Transplant Surgery, University Hospital Leipzig, Leipzig, Germany, ${ }^{4}$ Department of Radiology, Charité Campus Virchow Klinikum, Berlin, Germany, ${ }^{5}$ Leipzig University Medical Center, Integrated Center for Research and Treatment Adiposity Diseases, Leipzig, Germany, ${ }^{6}$ Internal Medicine (Endocrinology and Nephrology), University of Leipzig, Leipzig, Germany, ${ }^{7}$ Department of Endocrinology, Ludwig-Maximilians-University, Munich, Germany, ${ }^{8}$ Department of Diagnostic and Interventional Radiology, University Hospital Leipzig, Leipzig, Germany, ${ }^{9}$ Endokrinologie in Charlottenburg, Endokrinologie Praxis am Stuttgarter Platz, Berlin, Germany, and ${ }^{10}$ Department of Radiology, University Hospital Würzburg, Würzburg, Germany

Correspondence should be addressed to $S$ Hahner

Email

hahner_s@ukw.de

\begin{abstract}
Objective: Adrenal vein sampling (AVS) represents the current diagnostic standard for subtype differentiation in primary aldosteronism (PA). However, AVS has its drawbacks. It is invasive, expensive, requires an experienced interventional radiologist and comes with radiation exposure. However, exact radiation exposure of patients undergoing AVS has never been examined.

Design and methods: We retrospectively analyzed radiation exposure of 656 AVS performed between 1999 and 2017 at four university hospitals. The primary outcomes were dose area product (DAP) and fluoroscopy time (FT). Consecutively the effective dose (ED) was approximately calculated.

Results: Median DAP was found to be $32.5 \mathrm{~Gy}^{*} \mathrm{~cm}^{2}(0.3-3181)$ and FT $18 \mathrm{~min}(0.3-184)$. The calculated ED was $6.4 \mathrm{mSv}$ (0.1-636). Remarkably, values between participating centers highly varied: Median DAP ranged from 16 to $147 \mathrm{~Gy}^{*} \mathrm{~cm}^{2}$, FT from 16 to $27 \mathrm{~min}$, and ED from 3.2 to $29 \mathrm{mSv}$. As main reason for this variation, differences regarding AVS protocols between centers could be identified, such as number of sampling locations, frames per second and the use of digital subtraction angiographies.

Conclusion: This first systematic assessment of radiation exposure in AVS not only shows fairly high values for patients, but also states notable differences among the centers. Thus, we not only recommend taking into account the risk of radiation exposure, when referring patients to undergo AVS, but also to establish improved standard operating procedures to prevent unnecessary radiation exposure.
\end{abstract}

\section{Introduction}

Primary aldosteronism (PA) is the most common curable cause of secondary hypertension and characterized by the autonomous adrenocortical oversecretion of aldosterone leading to cardiovascular and metabolic complications $(1,2,3,4,5)$. Most commonly, the aldosterone excess either results from bilateral adrenal hyperplasia (BAH) or from a unilateral aldosterone-producing adenoma (APA) (6). Correct distinction between unilateral or bilateral disease is of high importance due to different therapeutic approaches: whereas PA due to APA may be cured by adrenalectomy, patients with BAH receive life-long treatment with mineralocorticoid receptor antagonists www.eje-online.org

https://doi.org/10.1530/EJE-18-0328 Printed in Great Britain
This work is licensed under a Creative Commons Attribution 4.0 International License.

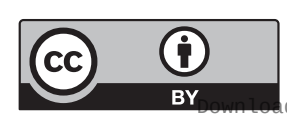

ded from Bioscientifica.com at $04 / 26 / 2023$ 07:27:56 AM 
(7). AVS is currently recommended as standard diagnostic tool for subtype differentiation in PA (2). However, AVS has its drawbacks: It is an invasive and expensive procedure with poor standardization regarding sampling protocols and interpretation of results among centers $(8$, $9,10)$. Success rates and complications such as adrenal hemorrhage also differ depending on the experience of the interventionalist $(11,12)$. Furthermore, there is not only an ongoing debate regarding the use of AVS itself (13, $14,15)$, but also its superiority in comparison to adrenal CT scan in terms of clinical outcome $(9,16)$. However, the SPARTACUS-trial raised controversial discussions itself due to its study design and patient selection $(15,17)$. The clinical usefulness of more recent approaches to replace AVS by molecular imaging is yet to be defined within clinical trials $(18,19)$.

Another argument brought forward against AVS is the potentially high radiation dose, to which patients are submitted during the procedure. Even though there are proven risks linked to radiation exposure, e.g. an increased incidence of cancer, to our knowledge, there is no available data so far addressing this particular problem. We, therefore, aimed to retrospectively analyze radiation exposure of AVS in four different specialized centers across Germany.

\section{Patients and methods}

\section{Patients}

We performed a retrospective analysis to assess radiation exposure caused by AVS. In all patients, informed consent for performance of AVS within clinical routine had been obtained in accordance with respective local regulations. The analysis was approved by the Ethics Committee of the University of Würzburg (AZ121/17). Overall, 658 AVS performed between 1999 and 2017 in Berlin (center 1, $n=53$ ), Leipzig (center 2, $n=52$ ), Munich (center 3, $n=400$ ) and Würzburg (center 4, $n=151$ ) with documented information regarding dose area product $\left(\mathrm{DAP}, \mathrm{Gy}^{*} \mathrm{~cm}^{2}\right)$, fluoroscopy time (FT, min) and, if available, performing radiologist and success of cannulation based on cortisol measurements were included in the analysis, without specific exclusion criteria. We furthermore collected information on sampling locations and imaging modalities for each center. Data were obtained at each participating center and sent to the coordinating center after anonymization.

\section{Assessment of radiation exposure}

Assessed radiation measures were FT (min), DAP $\left(\mathrm{Gy}^{*} \mathrm{~cm}^{2}\right)$ and effective dose $(\mathrm{ED}, \mathrm{mSv})$. FT constitutes for the amount of time during the procedure, in which fluoroscopy is used. It poorly correlates with other dose indicators. DAP is defined as the product of the radiation dose to air multiplied by the area of X-ray field, as measured by an ionization chamber mounted on the X-ray collimator. DAP is used to assess the radiation exposure of irrigated tissues and forms the basis for calculation of ED. ED represents the stochastic risk related to ionizing radiation and was approximately estimated as previously described: $\mathrm{ED}(\mathrm{mSv})=\mathrm{DAP}\left(\mathrm{Gy}^{*} \mathrm{~cm}^{2}\right) \times 0.2\left(\mathrm{mSv} / \mathrm{Gy}^{*} \mathrm{~cm}^{2}\right)(20)$.

Across participating sites the following angiography systems were used: Artis Zee, Axiom Artis XA C, Axiom Artis BA, Multistar TOP, Polystar XA (each Siemens Healthcare), Innova 4100 (GE Healthcare) and ALLURA Xper FD System (Philips Healthcare). For details, see Table 1.

\section{Statistical analysis}

Comparison of not normally distributed continuous data was performed using Mann-Whitney $U$ test. Normally distributed data are given as mean \pm S.D., whereas not normally distributed parameters are shown as median (min-max). Kruskal-Wallis test and post hoc analysis (Dunn-Bonferroni) were used to compare DAP and FT grouped by number of performed AVS. $P$ value $<0.05$ was considered statistically significant. SPSS version 24.0 (IBM) was used for statistical analysis.

\section{Results}

\section{General characteristics of AVS}

Overall, 658 procedures were assessed. Due to missing data for ED, DAP and FT, two patients were excluded from the study $(n=656)$. Median age of patients was 53 (16$85)$ years. Ten patients underwent AVS twice. Two centers (center 3, $n=400 / 400$; center $4, n=81 / 151$ ) used rapid cortisol measurements during AVS to determine correct catheter localization. At center 3, bilateral simultaneous catheterization of adrenal veins was carried out in 35\% of cases, whereas all other AVS procedures were performed as sequential catheterization. All AVS were performed without cosyntropin stimulation. Cannulation was successful in $80 \%$ of AVS with a large variability across 
Table 1 Overview of imaging modalities.

\begin{tabular}{|c|c|c|c|c|}
\hline Center & Angiography system & $\begin{array}{l}\text { Sampling locations number } \\
\text { (location) }\end{array}$ & DSA number (location) & Frames per second \\
\hline 1 & ALLURA Xper FD System & 6 (LAV, RAV, 2xLRV, 2xVCI) & $3 *(2 x R A V, L A V)$ & 2 \\
\hline 2 & Innova 4100 Axiom Artis BA & 6 (LAV, RAV, 2xVCI, RRV, LRV) & $2 *(\mathrm{LAV}, \mathrm{RAV})$ & 15 \\
\hline 3 & $\begin{array}{l}\text { Multistar TOP } \\
\text { Artis Zee MP } \\
\text { Axiom Artis XA C } \\
\text { Polystar XA }\end{array}$ & 3 (LAV, RAV, LFV or RFV) & 0 & 7.5 \\
\hline 4 & Artis Zee MP & 6 (LAV, RAV, VCI, VCS, RRV, LRV) & 6 (LAV, RAV, VCI, VCS, RRV, LRV) & 7.5 \\
\hline
\end{tabular}

*In case of unclear anatomy, additional DSA was performed.

DSA, digital subtraction angiography; LAV, left adrenal vein; LFV, left femoral vein; LRV, left renal vein; RAV, right adrenal vein; RFV, right femoral vein; RRV, right renal vein; VCI, Vena cava inferior; VCS, Vena cava superior.

participating centers Table 2. Success rate of AVS was significantly higher when cortisol measurements were performed during AVS (89 vs $56 \%, P<0.001$ ).

\section{DAP, ED and fluoroscopy time}

Median DAP across all centers was at $33 \mathrm{~Gy}^{*} \mathrm{~cm}^{2}(0.3-$ 3181). However, DAP showed high variation among institutions but also within the respective centers, ranging from $16.2 \mathrm{~Gy}^{*} \mathrm{~cm}^{2}(0.3-3181)$ up to $147 \mathrm{~Gy}^{*} \mathrm{~cm}^{2}(1.1-$ 1186) Table 3. Especially DAP values recorded at center 3 were significantly lower compared to center 1,2 and 4 respectively (all $P<0.001$ ) Fig. 1 . Calculated ED measured $6.5 \mathrm{mSv}$ (0.05-636), again displaying a high variability within and across the centers Table 3. Ten patients underwent AVS twice, leading to a median cumulative ED of $36 \mathrm{mSv}$ (0.92-113.95). Overall, FT was $18 \mathrm{~min}$ (0.3-184). FT varied from $16 \mathrm{~min}(0.3-184)$ at center 3 up to $27 \mathrm{~min}$ (4.0-116) at center 4 (3 vs $4 P \leq 0.001$ ). Table $3+$ Fig. 1. Furthermore, radiation exposure significantly increased with age. Whereas for example patients $\leq 40$ years $(n=78)$ received a median $\mathrm{ED}$ of $3.4 \mathrm{mSv}(0.1-237)$, patients
$>70$ years $(n=44)$ were exposed to $15 \mathrm{mSv}(1.2-178)$ $(P<0.001)$. Additionally, median ED was significantly lower in female patients ( 8.9 vs $4.0 \mathrm{mSv}, P<0.001)$.

Regarding experience level of performing radiologists, radiation exposure decreased with increasing numbers of performed procedures Fig. 2.

DAP, ED and FT were also significantly lower in successful AVS (FT successful cannulation $_{16} \mathrm{~min}$ (0.3-184), $\mathrm{FT}_{\text {unsuccessful cannulation }}=28 \mathrm{~min}(4.4-116), \mathrm{DAP}_{\text {successful cannulation }}=$ $25 \mathrm{~Gy}^{*} \mathrm{~cm}^{2}(0.3-3181), \mathrm{DAP}_{\text {unsuccessful cannulation }}=80 \mathrm{~Gy}^{*} \mathrm{~cm}^{2}$ (1.1-1186), $\mathrm{ED}_{\text {successful }}$ cannulation $=5.0 \mathrm{mSv} \quad(0.1-636)$, $\mathrm{ED}_{\text {unsuccessful cannulation }}=16 \mathrm{mSv}(0.2-237)$, all $\left.P<0,001\right)$. Over the period of 18 years, there were significant differences in DAP, ED and FT with predominantly consistent values in more recent years. Fig. 3. At center 3 DAP, ED and FT were significantly higher in cases of bilateral simultaneous catheterization compared to AVS with sequential catheterization of adrenal veins $\left(\mathrm{DAP}_{\text {simultaneous }}=27 \mathrm{~Gy}^{*} \mathrm{~cm}^{2}\right.$ (0.3-3181), $\mathrm{DAP}_{\text {sequential }}=14 \mathrm{~Gy}^{*} \mathrm{~cm}^{2}$ (0.8-423), $P<0.001$; $\mathrm{ED}_{\text {simultaneous }}=5.4 \mathrm{mSv} \quad(0.1-636), \quad \mathrm{ED}_{\text {sequential }}=2.8 \mathrm{mSv}$ (0.2-85), $\quad P<0.001 ; \quad \mathrm{FT}_{\text {simultaneous }}=18 \mathrm{~min} \quad(0.3-184)$, $\left.\mathrm{FT}_{\text {sequential }}=14 \mathrm{~min}(1.9-104), P=0.001\right)$.

Table 2 General characteristics on age, sex, rapid cortisol measurements and success of cannulation. Data are presented as \% (n) or as mean \pm S.D.

\begin{tabular}{|c|c|c|c|c|}
\hline Center & Age, mean \pm S.D. & Females & Males & $\begin{array}{c}\text { Cortisol } \\
\text { measurement }\end{array}$ \\
\hline $1(n=53)$ & $49 \pm 12$ & $45(24)$ & 55 (29) & No \\
\hline $2(n=52)$ & $55 \pm 12$ & $58(30)$ & $42(22)$ & No \\
\hline $3(n=400)$ & $52 \pm 11$ & $64(256)$ & 36 (144) & Yes \\
\hline $4(n=151)$ & $57 \pm 11$ & $38(57)$ & $62(94)$ & Yes \\
\hline Total & $53 \pm 11$ & $56(367)$ & 44 (289) & \\
\hline
\end{tabular}

\begin{tabular}{c} 
Bilateral \\
simultaneous \\
catheterization $\%(n)$ \\
\hline No \\
No \\
Yes; M: 35 (138) \\
No
\end{tabular}

\begin{tabular}{c} 
Cosyntropin \\
stimulation \\
\hline No \\
No \\
No \\
No
\end{tabular}

\begin{tabular}{c} 
Successful cannulation \% $(n)$ \\
\hline $59(31)$ \\
$61(31)$ \\
$90(361)$ \\
F: $50(35 / 70) * ; \mathrm{M}: 82(66 / 81) * *$ \\
$80(524)$
\end{tabular}

Center 2: $n=52$ ( $n=51$ for successful cannulation).

*AVS without rapid cortisol measurement; **AVS with rapid cortisol measurement. 
Table 3 Dose area product, effective dose and fluoroscopy time across participating centers. Values are displayed as median (min-max).

\begin{tabular}{|c|c|c|c|}
\hline Center & DAP $\left(\mathrm{Gy}^{*} \mathrm{~cm}^{2}\right)$ & ED (mSv) & FT $(\min )$ \\
\hline 1 & $147(1.1-1186)$ & $29(0.2-237)$ & $22(5.3-40)$ \\
\hline 2 & $48(10.0-610)$ & $9.6(2.0-122)$ & $20(0.8-50)$ \\
\hline 3 & $16(0.3-3181)$ & $3.2(0.1-636)$ & $16(0.3-184)$ \\
\hline 4 & $144(8.2-1166)$ & $29(1.6-233)$ & $27(4.0-116)$ \\
\hline
\end{tabular}

DAP, dose area product $\left(\mathrm{Gy}{ }^{*} \mathrm{~cm}^{2}\right) ; \mathrm{ED}$, effective dose $(\mathrm{mSv}) ; \mathrm{FT}$, fluoroscopy time (min).

\section{Sampling locations and imaging modalities}

Number of standard sampling locations varied between three (center 3) and six (centers 1, 2 and 4) (Details see Table 1). Digital subtraction angiography (DSA) was performed regularly in three centers (centers 1, 2 and 4) for two, three or all six locations, as well as in cases of unclear anatomy of the adrenal veins. In contrast, sampling locations in center 3 were documented just by using last image hold, but not an additional DSA. The number of frames per second ranged between 7.5 and 15. All centers used low-dose protocols implemented in respective X-ray system and reduced field of view to the necessary minimum. An overview of different imaging modalities is presented in Table 1 .

\section{Discussion}

In this study, we demonstrate that AVS is associated with a relevant exposure to radiation in some but not all centers who participated in this study. Even though overall ED measured $6.5 \mathrm{mSv}$, this was highly variable across participating centers and respective patients (0.1-636 mSv). Highest median ED for one center was at $29 \mathrm{mSv}$, a value equivalent to 1470 chest X-rays (21) and 12 times the natural background radiation of approximately $2.4 \mathrm{mSv}$ per year (22). For further reference, abdominal CT alone, routinely performed in patients with PA to assess the presence of nodules and for visualization of adrenal veins prior to AVS, is associated with an ED of approximately $10 \mathrm{mSv}$ (23).

It is well known that there are certain risks linked to radiation exposure, such as skin reactions, DNA damage and ultimately cancer induction (24). Whereas skin lesions and cataract are regarded as predictable deterministic effects occurring above a threshold radiation dose estimated at $500 \mathrm{mSv}$ (25), cancer induction represents a stochastic risk, making it nearly
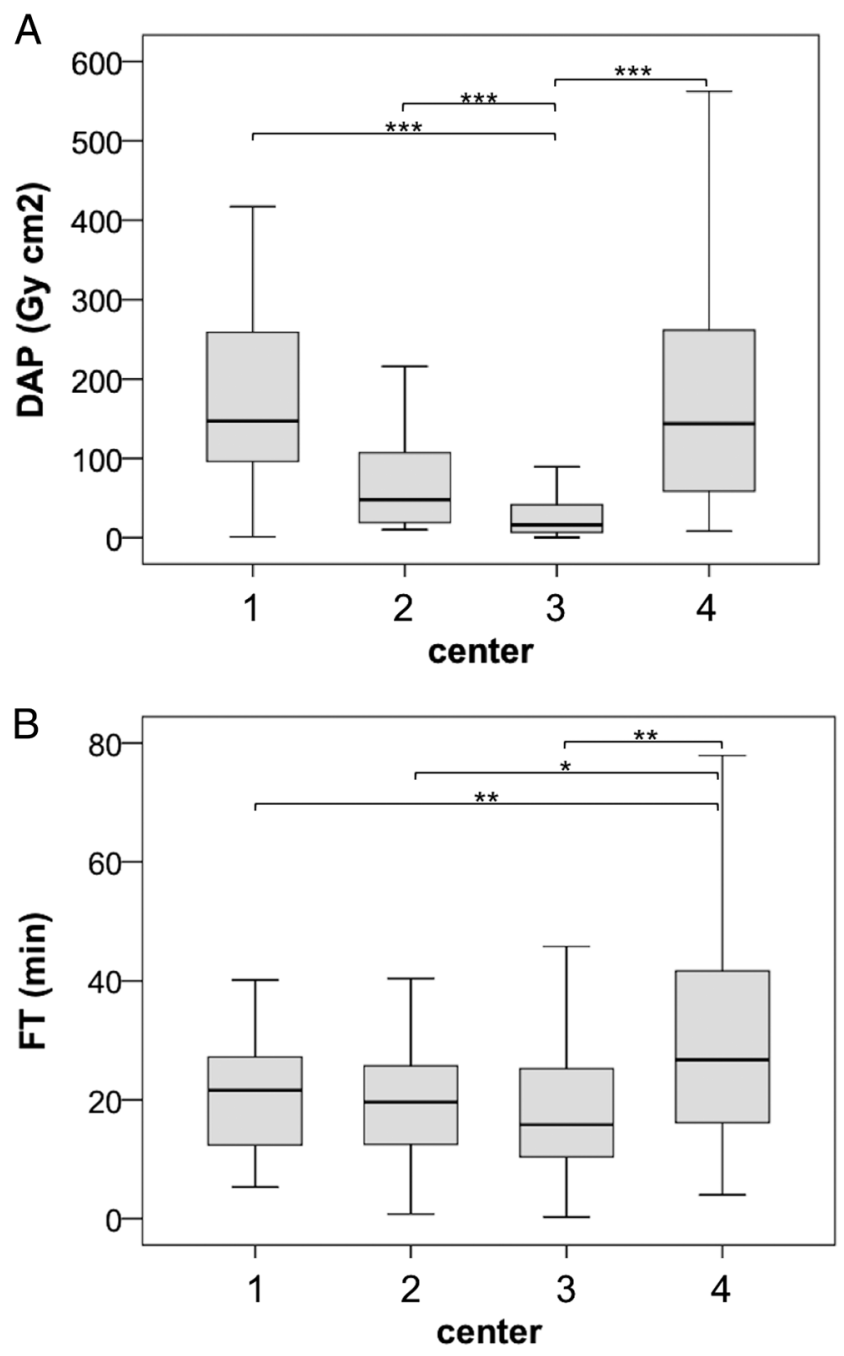

\section{Figure 1}

Dose area product (DAP, Gy* $\mathrm{cm}^{2}$ ) and fluoroscopy time (FT, min) in participating centers. (A) DAP, 1 vs $3 P<0.001,2$ vs $3 P<0.001,3$ vs $4 P<0.001$, (B) FT, 1 vs $4 P=0.001,2$ vs 4 $P=0.002,3$ vs $4 P<0.001 .{ }^{*} P \leq 0.05, * * P \leq 0.01, * * * P \leq 0.001$.

impossible to determine radiation as the specific cause of cancer in single patients, especially due to the long latency period between radiation exposure and clinical manifestations. Data available on malignancies in PA showed a lifetime malignancy occurrence of $9.6 \%$ in PA patients compared to $6.0 \%$ of hypertensive controls which, however, did not reach statistical significance $(P=0.08)$ (26). However, several diagnoses of malignancy had been made prior any AVS in this cohort (26) and long-term data on malignancy occurrence after AVS are so far missing.

Another main result of this study is the difference in radiation doses between participating institutions, 
which can be explained by the respective variation of imaging modalities. In contrast to all other centers, center 3 performed less samplings in fewer locations and, most importantly, did not use DSA for visualization of vascular structures at any point, but instead documented catheterization of adrenal veins by dynamic fluoroscopic sequences or using last image hold, allowing for the last image to be saved and displayed on the monitor after stopping fluoroscopy. The use of DSA causes approximately
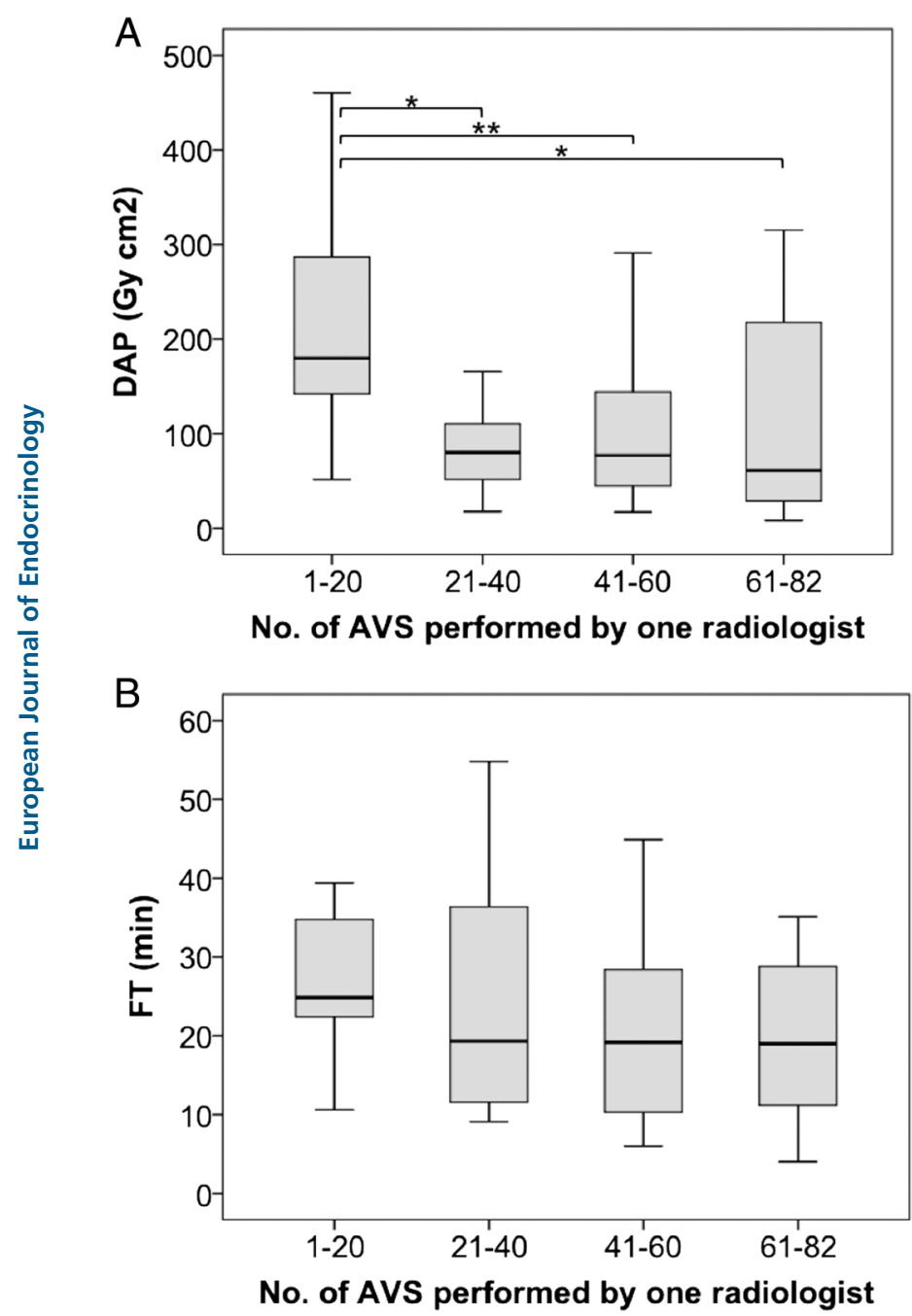

Figure 2

Changes in dose area product (DAP, Gy* $\mathrm{cm}^{2}$ ) and fluoroscopy time (FT, min) over time depending on the number of AVS performed by a single radiologist at center $4(n=82)$. $x$-axis = number of AVS in groups of 20 (22) AVS. (A) DAP, 1-20: 180 (52-461); 21-40: 80 (18-339); 41-60: 77 (17-291); 61-82: 61 (8.2-315); $1-20$ vs $21-40 P=0.011 ; 1-20$ vs $41-60 P=0.008 ; 1-20$ vs $60-82 P=0.013$. (B) FT, 1-20: 25 (11-86); 21-40: 19 (9.1-55); 41-60: 19 (6.0-45); 61-82: 19 (4.0-81). * $P \leq 0.05, * * P \leq 0.01$. ten times higher radiation doses compared to fluoroscopic sequences, therefore being not only a plausible, but also an adjustable factor explaining differences in radiation exposure across participating centers. Furthermore, the use of 7.5, instead of 15 or even 30 frames per second, the patient's distance from the X-ray tube and the detector, the correct use of collimators and the system settings used for performance of AVS account for more possible influencing parameters. Interestingly, bilateral
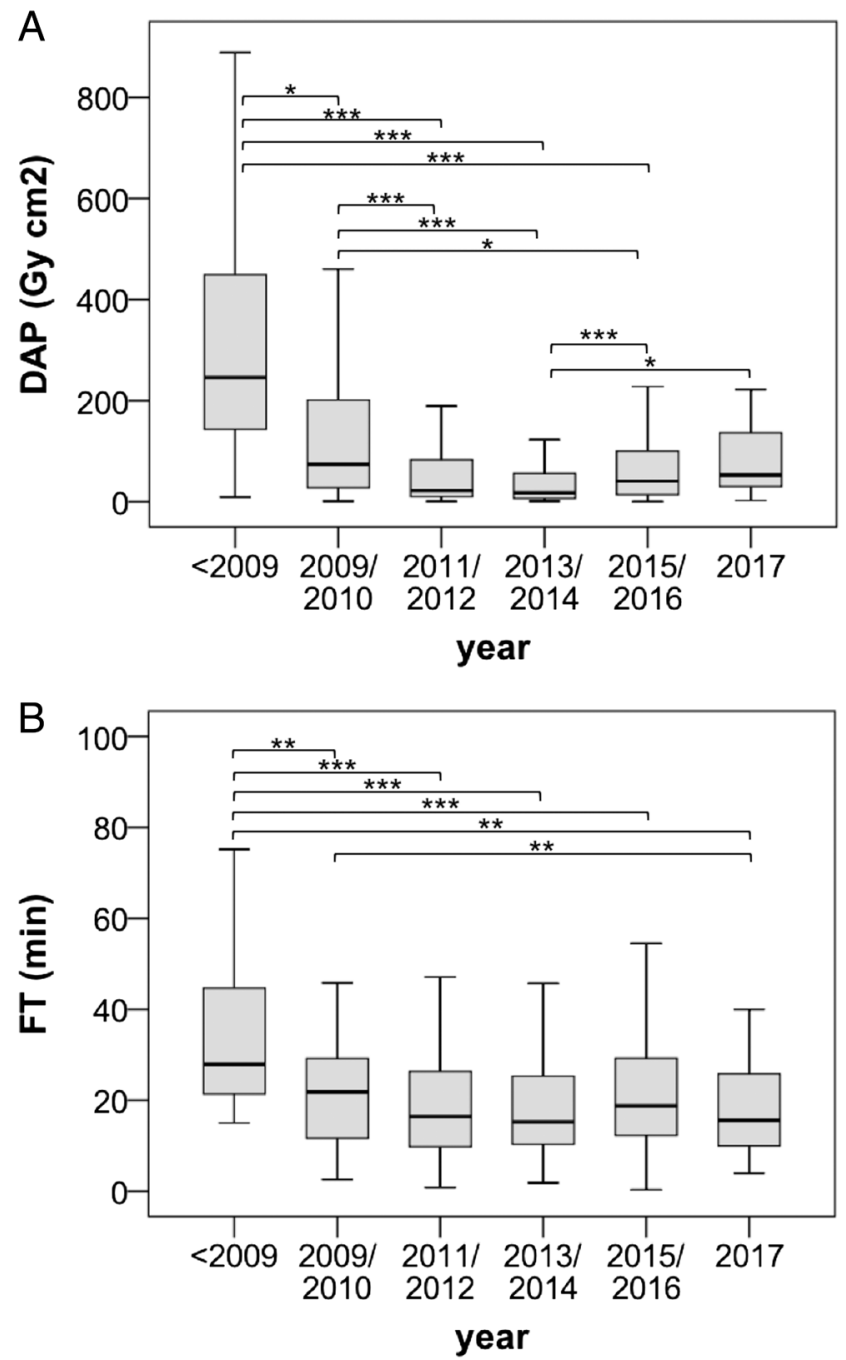

Figure 3

Dose area product ((A), DAP, Gy* $\left.\mathrm{cm}^{2}\right)$ and fluoroscopy time ((B), FT, min) across different years. <2009: $n=39$, DAP 246 (9.2-888), FT 28 (15-99); 2009/2010: $n=75$, DAP 74 (1.1-705), FT 22 (2.6-116); 2011/2012: $n=119$, DAP 22 (0.8-789), FT 16 (0.8-104); 2013/2014: $n=177$, DAP $18(1.2-1167)$, FT 15 (1.9-103); 2015/2016: $n=212$, DAP 41 (0.3-3181), FT 19 (0.3-184); 2017: $n=24$, DAP 53 (2.5-222), FT 16 (4.0-63). $* P \leq 0.05, * * P \leq 0.01, * * * P \leq 0.001$. 
simultaneous catheterization was associated with a significant increase in radiation exposure.

Based on the results of this study, there is obvious room for improvement regarding technical performance of AVS. To minimize radiation exposure, we recommend adopting some adjustments to currently applied protocols in the future: Documentation of adrenal veins should be done using predominantly last image hold, therefore limiting DSA to a minimum. Additionally, it seems possible to reduce number of sample locations to both adrenal veins and the inferior vena cava without compromising the validity and quality of AVS results, also resulting in lower FT and DAP. The radiation field should be limited to the necessary minimum. These adjustments should not only be considered to reduce patient exposure, but also the operator dose, mainly caused and determined by patient scatter (27). Our data furthermore indicate that the experience of the investigator is of relevance. In addition, centers performing rapid cortisol measurements during AVS showed much higher success rates of $>80 \%$ in comparison to those without application of this technique (28). Off note, this was not associated with higher EDs to the patients as similarly documented by a recent study (29). To avoid repeated AVS, it may therefore be postulated this procedure is performed in centers with sufficient volumes of investigations and that rapid cortisol measurement becomes standard, aiming at success rates comparable to available data $(28,29)$. In addition to implementing changes regarding execution of AVS, radiation exposure should generally be kept in mind, when making the decision to perform AVS, even more so in young patients.

There are some limitations to this study: Data on BMI of patients, a factor known to influence DAP, was not recorded (30). However, the vast differences observed between centers are unlikely to be caused predominantly by inhomogeneous distribution of BMI. Regarding variations in DAP, ED and FT between different years, data collection started at different time points at each center (1: 2008, 2: 1999, 3: 2009, 4: 2005). The significantly higher DAP, ED and FT of AVS performed from 1999 to $2008(n=39)$ and in 2009 compared to the following years can be attributed both to improved results over time in two centers and mainly by the absence of data from center 3 ( $<2009$ : $n=0$, 2009: $n=2$ ), therefore leading to higher values in general. However, it should be noted, that all participating centers were experienced in the performance of AVS.

In conclusion, this first systematic assessment shows that AVS may be associated with fairly high radiation exposure of patients with PA with significant differences across participating centers. We therefore not only suggest taking this risk into account when referring patients to undergo AVS, but also recommend the establishment and application of a common protocol to reduce and prevent unnecessary exposure to radiation.

Declaration of interest

The authors declare that there is no conflict of interest that could be perceived as prejudicing the impartiality of this study.

\section{Funding}

This work was supported by the Deutsche Forschungsgemeinschaft (DFG) (within the CRC/Transregio 205/1 'The Adrenal: Central Relay in Health and Disease') to S Hahner, M Reincke and M Fassnacht and by the Else KrönerFresenius Stiftung in support of the German Conns Registry-Else-Kröner Hyperaldosteronism Registry (2013_A182 and 2015_A171) to Martin Reincke.

\section{Acknowledgements}

The authors thank Dr Heribert Hänscheid, medical physicist at the Dept. of Nuclear Medicine, University Hospital Würzburg for his valuable advice.

\section{References}

1 Stowasser M. Primary aldosteronism in 2011: towards a better understanding of causation and consequences. Nature Reviews Endocrinology 20128 70-72. (https://doi.org/10.1038/ nrendo.2011.223)

2 Funder JW, Carey RM, Mantero F, Murad MH, Reincke M, Shibata H, Stowasser M \& Young WF Jr. The management of primary aldosteronism: case detection, diagnosis, and treatment: an Endocrine Society Clinical Practice Guideline. Journal of Clinical Endocrinology and Metabolism 2016101 1889-1916. (https://doi. org/10.1210/jc.2015-4061)

3 Born-Frontsberg E, Reincke M, Rump LC, Hahner S, Diederich S, Lorenz R, Allolio B, Seufert J, Schirpenbach C, Beuschlein F et al. Cardiovascular and cerebrovascular comorbidities of hypokalemic and normokalemic primary aldosteronism: results of the German Conn's Registry. Journal of Clinical Endocrinology and Metabolism 2009 94 1125-1130. (https://doi.org/10.1210/jc.2008-2116)

4 Mulatero P, Stowasser M, Loh KC, Fardella CE, Gordon RD, Mosso L, Gomez-Sanchez CE, Veglio F \& Young WF Jr. Increased diagnosis of primary aldosteronism, including surgically correctable forms, in centers from five continents. Journal of Clinical Endocrinology and Metabolism 200489 1045-1050. (https://doi.org/10.1210/jc.2003031337)

5 Hanslik G, Wallaschofski H, Dietz A, Riester A, Reincke M, Allolio B, Lang K, Quack I, Rump LC, Willenberg HS et al. Increased prevalence of diabetes mellitus and the metabolic syndrome in patients with primary aldosteronism of the German Conn's Registry. European Journal of Endocrinology 2015173 665-675. (https://doi.org/10.1530/ EJE-15-0450)

6 Rossi GP, Bernini G, Caliumi C, Desideri G, Fabris B, Ferri C, Ganzaroli C, Giacchetti G, Letizia C, Maccario M et al. A prospective study of the prevalence of primary aldosteronism in 1,125 hypertensive patients. Journal of the American College of Cardiology 200648 2293-2300. (https://doi.org/10.1016/j.jacc.2006.07.059)

7 Williams TA, Lenders JWM, Mulatero P, Burrello J, Rottenkolber M, Adolf C, Satoh F, Amar L, Quinkler M, Deinum J et al. Outcomes after 
adrenalectomy for unilateral primary aldosteronism: an international consensus on outcome measures and analysis of remission rates in an international cohort. Lancet Diabetes and Endocrinology 20175 689-699. (https://doi.org/10.1016/S2213-8587(17)30135-3)

8 Lethielleux G, Amar L, Raynaud A, Plouin PF \& Steichen O. Influence of diagnostic criteria on the interpretation of adrenal vein sampling. Hypertension 201565 849-854. (https://doi.org/10.1161/ HYPERTENSIONAHA.114.04812)

9 Kempers MJ, Lenders JW, van Outheusden L, van der Wilt GJ, Schultze Kool LJ, Hermus AR \& Deinum J. Systematic review: diagnostic procedures to differentiate unilateral from bilateral adrenal abnormality in primary aldosteronism. Annals of Internal Medicine 2009151 329-337. (https://doi.org/10.7326/0003-4819151-5-200909010-00007)

10 Rossi GP, Auchus RJ, Brown M, Lenders JW, Naruse M, Plouin PF, Satoh F \& Young WF Jr. An expert consensus statement on use of adrenal vein sampling for the subtyping of primary aldosteronism. Hypertension 201463 151-160. (https://doi.org/10.1161/ HYPERTENSIONAHA.113.02097)

11 Vonend O, Ockenfels N, Gao X, Allolio B, Lang K, Mai K, Quack I, Saleh A, Degenhart C, Seufert J et al. Adrenal venous sampling: evaluation of the German Conn's registry. Hypertension 201157 990-995. (https://doi.org/10.1161/HYPERTENSIONAHA.110.168484)

12 Rossi GP, Barisa M, Allolio B, Auchus RJ, Amar L, Cohen D, Degenhart C, Deinum J, Fischer E, Gordon R et al. The Adrenal Vein Sampling International Study (AVIS) for identifying the major subtypes of primary aldosteronism. Journal of Clinical Endocrinology and Metabolism 201297 1606-1614. (https://doi.org/10.1210/ jc.2011-2830)

13 Stewart PM \& Allolio B. Adrenal vein sampling for primary aldosteronism: time for a reality check. Clinical Endocrinology 201072 146-148. (https://doi.org/10.1111/j.1365-2265.2009.03714.x)

14 Rossi GP \& Funder JW. Adrenal vein sampling is the preferred method to select patients with primary aldosteronism for adrenalectomy: pro side of the argument. Hypertension 201871 5-9. (https://doi.org/10.1161/HYPERTENSIONAHA.117.09295)

15 Deinum J, Prejbisz A, Lenders JWM \& van der Wilt GJ. Adrenal vein sampling is the preferred method to select patients with primary aldosteronism for adrenalectomy: con side of the argument. Hypertension 201871 10-14. (https://doi.org/10.1161/ HYPERTENSIONAHA.117.09294)

16 Dekkers T, Prejbisz A, Kool LJS, Groenewoud H, Velema M, Spiering W, Kolodziejczyk-Kruk S, Arntz M, Kadziela J, Langenhuijsen JF et al. Adrenal vein sampling versus CT scan to determine treatment in primary aldosteronism: an outcome-based randomised diagnostic trial. Lancet Diabetes and Endocrinology 20164 739-746. (https://doi.org/10.1016/S2213-8587(16)30100-0)

17 Beuschlein F, Mulatero P, Asbach E, Monticone S, Catena C, Sechi LA \& Stowasser M. The SPARTACUS trial: controversies and unresolved issues. Hormone and Metabolic Research 201749 936-942. (https://doi. org/10.1055/s-0043-120524)

18 Burton TJ, Mackenzie IS, Balan K, Koo B, Bird N, Soloviev DV, Azizan EA, Aigbirhio F, Gurnell M \& Brown MJ. Evaluation of the sensitivity and specificity of (11)C-metomidate positron emission tomography (PET)-CT for lateralizing aldosterone secretion by Conn's adenomas. Journal of Clinical Endocrinology and Metabolism 201297 100-109. (https://doi.org/10.1210/jc.2011-1537)

19 Heinze B, Fuss CT, Mulatero P, Beuschlein F, Reincke M, Mustafa M, Schirbel A, Deutschbein T, Williams TA, Rhayem Y et al. Targeting
CXCR4 (CXC Chemokine Receptor Type 4) for molecular imaging of aldosterone-producing adenoma. Hypertension 201871 317-325. (https://doi.org/10.1161/HYPERTENSIONAHA.117.09975)

20 Le Heron JC. Estimation of effective dose to the patient during medical x-ray examinations from measurements of the dose-area product. Physics in Medicine and Biology 199237 2117-2126. (https:// doi.org/10.1088/0031-9155/37/11/008)

21 Mettler FA Jr, Huda W, Yoshizumi TT \& Mahesh M. Effective doses in radiology and diagnostic nuclear medicine: a catalog. Radiology 2008 248 254-263. (https://doi.org/10.1148/radiol.2481071451)

22 Mettler FA Jr, Bhargavan M, Faulkner K, Gilley DB, Gray JE, Ibbott GS, Lipoti JA, Mahesh M, McCrohan JL, Stabin MG et al. Radiologic and nuclear medicine studies in the United States and worldwide: frequency, radiation dose, and comparison with other radiation sources - 1950-2007. Radiology 2009253 520-531. (https:// doi.org/10.1148/radiol.2532082010)

23 Task Group on Control of Radiation Dose in Computed Tomography. Managing patient dose in computed tomography. A report of the International Commission on Radiological Protection. Annals of the ICRP 200030 7-45.

24 Stecker MS, Balter S, Towbin RB, Miller DL, Vano E, Bartal G, Angle JF, Chao CP, Cohen AM, Dixon RG et al. Guidelines for patient radiation dose management. Journal of Vascular and Interventional Radiology 200920 S263-S273. (https://doi.org/10.1016/j. jvir.2009.04.037)

25 Stewart FA, Akleyev AV, Hauer-Jensen M, Hendry JH, Kleiman NJ, Macvittie TJ, Aleman BM, Edgar AB, Mabuchi K, Muirhead CR et al. ICRP publication 118: ICRP statement on tissue reactions and early and late effects of radiation in normal tissues and organs - threshold doses for tissue reactions in a radiation protection context. Annals of the ICRP 201241 1-322. (https://doi.org/10.1016/j.icrp.2012.02.001)

26 Lang K, Weber K, Quinkler M, Dietz AS, Wallaschofski H, Hannemann A, Friedrichs N, Rump LC, Heinze B, Fuss CT et al. Prevalence of malignancies in patients with primary aldosteronism. Journal of Clinical Endocrinology and Metabolism 2016101 1656-1663. (https://doi.org/10.1210/jc.2015-3405)

27 Miller DL, Vano E, Bartal G, Balter S, Dixon R, Padovani R, Schueler B, Cardella JF \& de Baere T. Occupational radiation protection in interventional radiology: a joint guideline of the Cardiovascular and Interventional Radiology Society of Europe and the Society of Interventional Radiology. CardioVascular and Interventional Radiology 201033 230-239. (https://doi.org/10.1007/ s00270-009-9756-7)

28 Betz MJ, Degenhart C, Fischer E, Pallauf A, Brand V, Linsenmaier U, Beuschlein F, Bidlingmaier M \& Reincke M. Adrenal vein sampling using rapid cortisol assays in primary aldosteronism is useful in centers with low success rates. European Journal of Endocrinology 2011 165 301-306. (https://doi.org/10.1530/EJE-11-0287)

29 Page MM, Taranto M, Ramsay D, van Schie G, Glendenning P, Gillett MJ \& Vasikaran SD. Improved technical success and radiation safety of adrenal vein sampling using rapid, semiquantitative point-of-care cortisol measurement. Annals of Clinical Biochemistry 20184563218760352 . (https://doi. org $/ 10.1177 / 0004563218760352)$

30 Ector J, Dragusin O, Adriaenssens B, Huybrechts W, Willems R, Ector $\mathrm{H} \&$ Heidbüchel H. Obesity is a major determinant of radiation dose in patients undergoing pulmonary vein isolation for atrial fibrillation. Journal of the American College of Cardiology $2007 \mathbf{5 0}$ 234-242. (https://doi.org/10.1016/j.jacc.2007.03.040)
Received 17 April 2018

Revised version received 9 July 2018

Accepted 31 July 2018 